\title{
Dosimetric characteristics of a thin bolus made with real time variable shape tungsten rubber for photon radiotherapy
}

\section{Katsuya Okuhata}

Graduate School of Medical Sciences, Kindai University

Hajime Monzen ( $\nabla$ hmon@med.kindai.ac.jp )

Graduate School of Medical Sciences, Kindai University

Mikoto Tamura

Graduate School of Medical Sciences, Kindai University

Yasumasa Nishimura

Faculty of Medicine, Kindai University

\section{Research Article}

Keywords: Real time variable shape, Tungsten rubber, Thin bolus, Photon radiotherapy

Posted Date: May 25th, 2021

DOl: https://doi.org/10.21203/rs.3.rs-546563/v1

License: (c) (i) This work is licensed under a Creative Commons Attribution 4.0 International License.

Read Full License 


\section{Abstract}

In this study, we aim to clarify the dosimetric characteristics of a real time variable shape rubber containing tungsten (STR) as a thin bolus in 6-MV photon radiotherapy. The percentage depth doses (PDDs) and lateral dose profiles (irradiation field $=10 \times 10 \mathrm{~cm}^{2}$ ) in the water-equivalent phantom were measured and compared between no bolus, a conventional 5-mm gel bolus, and 1-, 2-, and 3-mm STR boluses. The characteristics of the PDDs were evaluated according to relative doses at $1 \mathrm{~mm}$ depth $\left(D_{1 \mathrm{~mm}}\right)$ and depth of maximum dose $\left(d_{\max }\right)$. The water-equivalent thicknesses of the STR boluses were determined by shifting the distance of the PDD's build-up curve until it overlaid that with no bolus. The penumbra size and width of the $50 \%$ dose were evaluated using lateral dose profiles. The $D_{1 \mathrm{~mm}}$ with no bolus, 5-mm gel bolus, and 1-, 2-, and 3-mm STR boluses were $47.6 \%, 91.5 \%, 86.6 \%, 89.3 \%$, and $89.4 \%$, respectively, and the respective $d_{\max }$ values were $15,10,12,11$, and $10 \mathrm{~mm}$. The water-equivalent thicknesses of the 1-, 2-, and 3-mm STR boluses were 4.4, 4.9, and $5.1 \mathrm{~mm}$, respectively. There were no differences for those in lateral dose profiles. The 1-mm-thick STR thin bolus shifted the depth dose profile by $4.4 \mathrm{~mm}$ and could be used as a customized bolus for photon radiotherapy.

\section{Introduction}

The use of megavolt photon beams for superficial targets has increased through the intensity modulated radiotherapy (IMRT) or volumetric modulated arc therapy (VMAT) techniques [1, 2] and treatment devices, such as the Halcyon (Varian Medical Systems Inc., Palo Alto, CA) and TomoTherapy (Accuray, Sunnyvale, CA, USA) [3] that employ only 6-MV photon beams instead of electron beams. Prescription of a sufficient dose to superficial targets is difficult in photon radiotherapy because of the skin sparing effect $[2,4-6]$. A bolus composed of water- or tissue-equivalent materials have been commonly used by setting it on a target on the patient's surface to shift the depth dose distribution toward the skin surface (bolus effect) [7] and enhance the prescribed dose to the superficial target $[4,5]$.

A thin bolus is useful to insert under the original mask in head-and-neck cases (e.g., superficial lymph nodes included in the planning target volume) without affecting the fit of the mask or the localization of the treatment for IMRT/VMAT [8]. Some reports have investigated a three-dimensional (3D)-printed bolus to improve adhesion to the patient. The materials of the 3D-printed bolus, such as acrylonitrile butadiene styrene (ABS), polylactic acid (PLA) and silicone rubber, need to have the water-equivalent thickness desired for the bolus effect $[8,9]$. A 0.15 -cm-thick shape memory bolus that can be adapted along the body surface by heating and reused [5]. The bolus effect was minimal as a thin bolus because its density was comparable to water. The thin bolus requires a high density or high atomic number to enhance the surface dose adequately. The commercially available brass mesh bolus and 3D-printed bolus made of copper-plastic composite material (copper-plastic bolus) has a high atomic number and also has good adhesion to the body surface $[8,10]$. The surface dose using a brass mesh (thickness $=1.0 \mathrm{~mm}$ ) and copper-plastic bolus (thickness $=0.8 \mathrm{~mm}$ ) were at most $44 \%$ and $67 \%$ of a $6-\mathrm{MV}$ photon beam's maximum depth dose, respectively $[8,10]$. On the other hand, the surface doses of commercially available 
vinyl gel sheet bolus (thickness $=5 \mathrm{~mm}$ ) was $87 \%$ [10]. A material with a higher atomic number should be used as a thin bolus to adequately enhance the surface dose.

We have developed tungsten-containing materials such as tungsten containing rubber [11-13] and tungsten functional paper [14-19], while those do not adhere well to the body surface. Real time variable shape rubber containing tungsten (STR; Hayakawa Rubber Co., Ltd. Hiroshima, Japan), which has a density of $7.3 \mathrm{~g} / \mathrm{cm}^{3}$, can be manually formed to any shape by hand when warmed to approximately $60^{\circ} \mathrm{C}$, and its shape maintains at body or room temperature [20-23]. STR has the potential to be used as a bolus by stretching it thin and fitting it to the patient's contour. The purpose of this study was to clarify the physical and dosimetric characteristics of STR as a thin bolus for 6-MV photon beams. STR's physical characteristics such as hardness, tensile strength, and elongation were evaluated to investigate the material's physical strength. Enhancement of the surface dose using STR with 1-, 2-, and 3-mm thicknesses was also investigated and compared with that using commercially available vinyl gel sheet boluses with 5- or 10-mm thickness. The advantages and disadvantages of STR with respect to physical strength and dosimetric characteristics were also discussed.

\section{Methods}

\section{Physical characteristics of STR}

STR is a rubber material with no cross-linking polymerization. After heating the STR wrapped in clingfilm with a 700-W microwave oven for $1 \mathrm{~min}$ [22], it was rolled out to a sheet of uniform thickness by hand or using a stick such as a rolling pin between $1 \mathrm{~mm}$-thick acrylic plates. That was repeated until the STR was stretched to a thickness of $1 \mathrm{~mm}$. The elemental ratio of the STR (wt\%) is C: $5.5 \%, \mathrm{H}: 0.9 \%, 0: 1.4 \%$, and W: $92.2 \%$ [20]. The STR bolus can be formed to fit the contours of the face in real time, as shown in Figure 1.

The hardness of the STR was measured using a type-A durometer according to Japanese Industrial Standard (JIS) K6253 [24]. The hardness was defined as the resistance force of a material when it was pressed at a single point with the indentor [9]. The durometer readings (hardness values of 0,50 , and 100 ) indicated resistance forces of 550,4300 , and $8050 \mathrm{mN}$, respectively. A larger value for hardness indicated greater rigidity. The tensile strength and elongation were determined by the relationship between the tensile stress and elongation rate according to JIS K6251 [25]. The elongation rate was obtained by stretching the test piece of STR $(2.0 \pm 0.2-\mathrm{mm}$ thickness $)$ with each tensile stress. The tensile strength and elongation were defined as maximum tensile stress and maximum elongation rate at breaking point of the test piece of STR, respectively. Each test was performed at simulated room and body temperatures $\left(20^{\circ} \mathrm{C}\right.$ and $36^{\circ} \mathrm{C}$, respectively). The hardness, tensile strength, and elongation were compared with the corresponding values of silicone rubber bolus [9].

\section{Experimental setup of dosimetric characteristics}


The irradiated field was $10 \times 10 \mathrm{~cm}^{2}$ at a distance of $100 \mathrm{~cm}$ from the source to surface of the waterequivalent phantom (Tough Water; Kyoto Kagaku, Co., Ltd., Kyoto, Japan) (Figure 2(a) and (b)). The thicknesses of the STR boluses were 1-, 2-, and 3-mm, and we used STR boluses of size $150(\mathrm{~W}) \times 150(\mathrm{~L})$ $\mathrm{mm}^{2}$ supplied by Hayakawa Rubber $\mathrm{Co}$. to minimize the uncertainty of the thickness. The dimensions of the gel bolus (MTCB455S and MTCB450S; CIVCO, IA, USA) were $150(\mathrm{~W}) \times 150(\mathrm{~L}) \times 5$ or $10(\mathrm{~T}) \mathrm{mm}^{3}$. The STR bolus or gel bolus was placed on the water-equivalent phantom, and 200 monitor units were irradiated using a linear accelerator (Elekta synergy; Elekta AB, Sweden).

\section{Dosimetric characteristics of the STR bolus with 6-MV photon beams}

The percentage depth dose (PDD) was measured with a parallel plate ionization chamber (PPC40; IBA Dosimetry, Germany) for the 6-MV photon beam (Figure 2(a)). The characteristics of the PDDs were evaluated according to the depth of maximum dose $\left(d_{\max }\right)$ and the relative doses at $1 \mathrm{~mm}, 50 \mathrm{~mm}$, and $100 \mathrm{~mm}$ depth $\left(D_{1 \mathrm{~mm}}, D_{50 \mathrm{~mm}}\right.$, and $D_{100 \mathrm{~mm}}$, respectively). The water-equivalent thickness of the STR bolus was determined by shifting the distance of the build-up curve in the PDD until it overlaid that for the no bolus [10].

The lateral dose profiles were measured with radiochromic film (Gafchromic EBT3; Ashland, Inc., Covington, KY, USA). The film was set up perpendicular to the beam axis at the surface and at depths of $50 \mathrm{~mm}$ and $100 \mathrm{~mm}\left(d_{50 \mathrm{~mm}}\right.$ and $d_{100 \mathrm{~mm}}$, respectively) in the water-equivalent phantom (Figure 2(b)). The irradiated films were scanned by a digital scanner (ES-10000G; Epson Corp., Nagano, Japan) at least 24 hours after irradiation [26]. The scanned film was analyzed with a DD-System (version 10.3, R-TECH, Inc., Tokyo, Japan) using the 16-bit red channel and 150-dots-per-inch resolution. The lateral dose profile was normalized to the dose at center of the beam axis, and the penumbra size (as the width of the off-axis distance from $80 \%$ to $20 \%$ dose levels, $\left.P_{80-20}\right)$ and $50 \%$ dose width $\left(W_{50}\right)$ were evaluated at the surface, $d_{50 \mathrm{~mm}}$, and $d_{100 \mathrm{~mm}}$.

\section{Results}

\section{Physical characteristics of STR}

The hardness, tensile strength, and elongation are summarized in Table 1. The relationships between tensile stress and elongation rate at $20^{\circ} \mathrm{C}$ and $36^{\circ} \mathrm{C}$ are shown in Fig. 3 . The hardness of STR at $20^{\circ} \mathrm{C}$ was approximately 1.2 times higher than that at $36^{\circ} \mathrm{C}$. The hardness at $36^{\circ} \mathrm{C}$ was 57 , which maintained a constant thickness with a load of at least $4300 \mathrm{mN}$ at a point. The strain at the maximum stress of STR was approximately $15 \%$ for both temperatures at both temperatures, while the stress at $20^{\circ} \mathrm{C}$ was stronger than that at $36^{\circ} \mathrm{C}$. The STR was more than five times harder and less elongated than silicone rubber bolus at $36^{\circ} \mathrm{C}[9]$, but the tensile strength of the STR was lower than that of the silicone rubber bolus. 
Table 1

Hardness, tensile strength, and elongation at breaking point of STR bolus and silicone rubber bolus [9].

\begin{tabular}{|llll|}
\hline & \multicolumn{2}{l}{ STR bolus } & Silicone rubber bolus [9] \\
\cline { 2 - 4 } & $\mathbf{2 0 ^ { \circ } \mathrm { C }}$ & $\mathbf{3 6}^{\circ} \mathrm{C}$ & Not applicable \\
\hline Hardness (Type-A) & 67 & 57 & 10 \\
\hline$\square$ Tensile strength (MPa) & 1.67 & 1.21 & 3.28 \\
\hline$\square$ Elongation (\%) & 20 & 30 & 1000 \\
\hline
\end{tabular}

\section{Dosimetric characteristics of megavoltage photon beams with the STR bolus}

The PDDs are shown in Fig. 4, and the dosimetric characteristics of the PDDs are shown in Table 2. $D_{1 \mathrm{~mm}}$ with the 5-mm gel bolus and STR boluses with thicknesses of 1-, 2-, and 3-mm were increased by $43.9 \%$, $39.0 \%, 41.7 \%$, and $41.8 \%$ compared with that of the no bolus condition, respectively. The $D_{1 \mathrm{~mm}}$ value was increased by $2.8 \%$ when the thickness of the STR bolus was increased from 1 to $3 \mathrm{~mm}$. The PDD values around $d_{\max }( \pm 1.0 \mathrm{~mm})$ of the $1-, 2-$, and 3-mm STR boluses were within $1.0 \%$ of each other. The waterequivalent thicknesses of the 1-, 2-, and 3-mm STR boluses were 4.4, 4.9, and $5.1 \mathrm{~mm}$, respectively. Thus, the differences in water-equivalent thickness were within $1 \mathrm{~mm}$.

The lateral dose profiles of the 5-mm gel bolus and the 1-, 2-, and 3-mm STR boluses are shown in Fig. 5, and their dosimetric characteristics are shown in Table 3. The $P_{80-20}$ and $W_{50}$ values were almost equal between the 5-mm gel bolus and the 1-, 2-, and 3-mm STR boluses.

Table 2

$d_{\text {max }}, D_{1 \mathrm{~mm}}, D_{50 \mathrm{~mm}}$, and $D_{100 \mathrm{~mm}}$ of no bolus, gel boluses, and STR boluses.

\begin{tabular}{|c|c|c|c|c|c|c|}
\hline & \multirow[t]{2}{*}{ No bolus } & \multicolumn{2}{|c|}{ Gel bolus } & \multicolumn{3}{|c|}{ STR bolus } \\
\hline & & 5-mm & $10-\mathrm{mm}$ & 1-mm & 2-mm & 3-mm \\
\hline$d_{\max }(\mathrm{mm})$ & 15.0 & 10.0 & 5.0 & 12.0 & 11.0 & 10.0 \\
\hline$D_{1 \mathrm{~mm}}(\%)$ & 47.6 & 91.5 & 99.0 & 86.6 & 89.3 & 89.4 \\
\hline$D_{50 \mathrm{~mm}}(\%)$ & 86.8 & 84.3 & 81.9 & 85.2 & 84.6 & 84.2 \\
\hline$D_{100 m m}(\%)$ & 67.2 & 65.2 & 63.3 & 65.3 & 64.9 & 64.2 \\
\hline
\end{tabular}


Table 3

Width of $50 \%$ dose $\left(W_{50}\right)$ and penumbra (as the width of the off-axis distance from $80-20 \%$ dose levels, $\left.P_{80}-20\right)$ for surface, $d_{50 \mathrm{~mm}}$, and $d_{100 \mathrm{~mm}}$ in water-equivalent phantom.

\begin{tabular}{|lllll|}
\hline & Gel Bolus & \multicolumn{2}{l|}{ STR bolus } \\
\cline { 3 - 5 } & $\mathbf{5 - m m}$ & 1-mm & 2-mm & 3-mm \\
\hline$W_{50}(\mathrm{~mm})$ & & & & \\
\hline Surface & 100.3 & 100.5 & 99.5 & 99.5 \\
\hline$d_{50 \mathrm{~mm}}$ & 105.7 & 106.4 & 105.4 & 105.5 \\
\hline$d_{100 \mathrm{~mm}}$ & 110.3 & 110.2 & 110.5 & 110.2 \\
\hline$P_{80-20}(\mathrm{~mm})$ & & & & \\
\hline Surface & 4.4 & 3.9 & 4.3 & 4.4 \\
\hline$d_{50 \mathrm{~mm}}$ & 5.5 & 5.5 & 6.1 & 6.1 \\
\hline$d_{100 \mathrm{~mm}}$ & 6.1 & 6.2 & 6.6 & 6.3 \\
\hline$d_{X \mathrm{~mm}}:$ depth of $X \mathrm{~mm}$. & & & \\
\hline
\end{tabular}

\section{Discussion}

In this study, we clarified the physical and dosimetric characteristics of the thin STR bolus. Even at body temperature, the hardness of STR is more resistant to pressure than that of the silicone rubber bolus and can maintain a constant thickness [9]. The STR also showed almost no elongation compared with the commercial silicone rubber bolus $[9,11-13]$. Therefore, the thin STR is sufficiently rigid and can maintain its shape at room and body temperatures for clinical use and adhere to the patient's contour (Fig. 1) in real time. The STR bolus with thickness of only $1 \mathrm{~mm}$ provided a comparable bolus effect and dosimetric characteristics to those of the conventional 5-mm gel bolus and fit well to the patient's contour, suggesting the potential use of STR as a thin bolus in 6-MV photon radiotherapy.

With 6-MV photon beams, differences in PDD curve and water-equivalent thickness were not observed between 1-, 2-, and 3-mm STR boluses. The dose to the build-up region provided by secondary electrons from the STR bolus is almost equal between the 1-, 2-, and 3-mm STR boluses because of the absorption of secondary electrons in the STR bolus [7]. Furthermore, differences in lateral dose profiles were not observed at each depth and thickness of the STR bolus, and the bolus did not expand the penumbra because of its absorption of secondary electrons $[7,27]$. The manual shaping of the STR may cause variation of the thickness. The differences of the surface dose and $d_{\max }$ between the 1- and 2-mm STR 
boluses were $2.7 \%$ and $1 \mathrm{~mm}$, respectively. Even if the variation of STR thickness is $1.5 \pm 0.5 \mathrm{~mm}$, the uncertainty of the dose in the build-up region is within $2.7 \%$ (Fig. 5), which means that the material can be processed into thin sheets without using any especially precise technique.

When the other metal boluses were used with 6-MV photon beams, a copper-plastic composite material (density $=3.33 \mathrm{~g} / \mathrm{cm}^{3}$ ) with a thickness of $0.4 \mathrm{~mm}$ had only a $1.2-\mathrm{mm}$ water-equivalent thickness [8]. Furthermore, a brass mesh bolus with a thickness of $1 \mathrm{~mm}$ had only a 1.1-mm water-equivalent thickness [10], and it increased the $D_{1 \mathrm{~mm}}$ by only $17 \%$ compared with no bolus [28]. The newly developed eXaSkin (Anatomical Geometry S.L.) can be shaped in a short time, but the complicated process of manual mixing of eXaSkin and its catalyzer for a few minutes is required for hardening. The density of eXaSkin is 1.59 $\mathrm{g} / \mathrm{cm}^{3}$, requires the desired water-equivalent thickness to achieve the bolus effect, like the 3D-printed boluses made of ABS and PLA [29]. The advantages of the STR bolus include its use of tungsten to enhance the surface dose by increasing scattered radiation at thin thickness values and its simple shapability in real time [10]. We expect that STR can be effectively used as a thin bolus in some clinical cases of postmastectomy radiation therapy, head and neck cancers with superficial targets, nasal lymphomas, and extensive scalp malignancies with conformal radiotherapy or IMRT/VMAT instead of those conventional boluses. The limitation of the thin STR bolus is that it cannot be used for CT simulations because it attenuates kilovoltage X-rays and generates metal artifacts. However, a process of calculation of the dose distribution for treatment planning, virtual bolus with the water- or tissueequivalent thickness of the STR might be solved this limitation [8].

\section{Conclusion}

The 1-mm STR thin bolus shifted the depth dose profile by $4.4 \mathrm{~mm}$ toward the skin surface and exhibited excellent adhesion to the body surface. It could be used as a customized bolus for photon radiotherapy.

\section{Declarations}

\section{Acknowledgments}

We thank Mr. Masafumi Shigita and Mr. Yoshito Kadowaki for their support. We also thank Richard Lipkin, PhD, from Edanz Group (https://en-author-services.edanz.com/ac) for editing a draft of this manuscript.

\section{Funding}

This work was supported partly by Japan Society for the Promotion of Science (JSPS) KAKENHI [grant numbers 19K08211, 19K17213].

\section{Conflict of interest}

Hajime Monzen received a research donation from Hayakawa Rubber Co., Ltd. 
Availability of data and material

The data that support the findings of this study are available from the corresponding author upon reasonable request.

\section{Ethics approval}

This article does not involve any studies with human participants or animals performed by any of the authors.

\section{Informed consent}

This article does not involve patient data.

\section{Authors' contributions}

$\mathrm{KO}, \mathrm{HM}$, and MT designed the study and the analysis. KO performed the measurement and analysis the data. $\mathrm{KO}, \mathrm{HM}$, and MT performed interpretation the data. $\mathrm{KO}, \mathrm{HM}, \mathrm{MT}$, and $\mathrm{YN}$ prepared manuscript. All authors collaborated on writing the manuscript, read and approved the final manuscript.

\section{References}

1. Mahdavi JM, Petersen TH, Sjölin M, Behrens CF, Mahmood F (2015) PO-0838: Determination of the effect on patient surface dose from unwanted air cavities under bolus in VMAT. Radiother Oncol 115:S424. https://doi.org/10.1016/S0167-8140(15)40830-8

2. Boman E, Ojala J, Rossi M, Kapanen M (2018) Monte Carlo investigation on the effect of air gap under bolus in post-mastectomy radiotherapy. Phys Med 55:82-87. https://doi.org/10.1016/j.ejmp.2018.10.023

3. Ashburner MJ, Tudor S (2014) The optimization of superficial planning target volumes (PTVs) with helical tomotherapy. J Appl Clin Med Phys 15:4-12. https://doi.org/10.1120/jacmp.v15i6.4560

4. Khan FM, Gibbons JP (2014) Khan's the physics of radiation therapy, 5th edition. Lippincott Williams \& Wilkins, Baltimore

5. Aoyama T, Uto K, Shimizu H, Ebara M, Kitagawa T, Tachibana H, Suzuki K, Kodaira T (2020) Physical and dosimetric characterization of thermoset shape memory bolus developed for radiotherapy. Med Phys 47:6103-6112. https://doi.org/10.1002/mp.14516

6. Luu A, Doerwald-Munoz L, Ostapiak O (2015) An Evaluation of Two Approaches to Skin Bolus Design for Patients Receiving Radiotherapy for Head and Neck Cancers. J Med Imaging Radiat Sci 46:S37-S42. https://doi.org/10.1016/j.jmir.2014.08.001

7. Ciesielski B, Reinstein LE, Wielopolski L, Meek A (1989) Dose enhancement in buildup region by lead, aluminum, and lucite absorbers for 15 MVp photon beam. Med Phys 16:609-613.

https://doi.org/https://doi.org/10.1118/1.596362 
8. Ehler ED, Sterling DA (2020) 3D printed copper-plastic composite material for use as a radiotherapy bolus. Phys Med 76:202-206. https://doi.org/10.1016/j.ejmp.2020.07.008

9. Park JM, Son J, An HJ, Kim JH, Wu HG, Kim JI (2019) Bio-compatible patient-specific elastic bolus for clinical implementation. Phys Med Biol 64:. https://doi.org/10.1088/1361-6560/ab1c93

10. Richmond ND, Daniel JM, Whitbourn JR, Greenhalgh AD (2016) Dosimetric characteristics of brass mesh as bolus under megavoltage photon irradiation. Br J Radiol 89:20150796. https://doi.org/10.1259/bjr.20150796

11. Kijima K, Monzen H, Matsumoto K, Tamura M, Nishimura Y (2018) The shielding ability of novel tungsten rubber against the electron beam for clinical use in radiation therapy. Anticancer Res 38:3919-3927. https://doi.org/10.21873/anticanres.12677

12. Kijima K, Krisanachinda A, Tamura M, Nishimura Y, Monzen H (2019) Feasibility of a Tungsten Rubber Grid Collimator for Electron Grid Therapy. Anticancer Res 39:2799-2804. https://doi.org/10.21873/anticanres.13407

13. Kijima K, Krisanachinda A, Tamura M, Monzen H, Nishimura Y (2020) Reduction of Occupational Exposure Using a Novel Tungsten-Containing Rubber Shield in Interventional Radiology. Health Phys 118:609-614. https://doi.org/10.1097/HP.0000000000001177

14. Tamura M, Monzen H, Kubo K, Hirata M, Nishimura Y (2017) Feasibility of tungsten functional paper in electron grid therapy: a Monte Carlo study. Phys Med Biol 62:878-889. https://doi.org/10.1088/1361-6560/62/3/878

15. Takei Y, Kamomae T, Monzen H, Nakaya T, Sugita K, Suzuki K, Oguchi H, Tamura M, Nishimura Y (2020) Feasibility of using tungsten functional paper as a thin bolus for electron beam radiotherapy. Phys Eng Sci Med 43:1101-1111. https://doi.org/10.1007/s13246-020-00910-2

16. Kamomae T, Monzen H, Kawamura M, Okudaira K, Nakaya T, Mukoyama T, Miyake Y, Ishihara Y, Itoh $Y$, Naganawa S (2017) Dosimetric feasibility of using tungsten-based functional paper for flexible chest wall protectors in intraoperative electron radiotherapy for breast cancer. Phys Med Biol 63:015006. https://doi.org/10.1088/1361-6560/aa96cf

17. Inada M, Monzen H, Matsumoto K, Tamura M, Minami T, Nakamatsu K, Nishimura Y (2018) A novel radiation-shielding undergarment using tungsten functional paper for patients with permanent prostate brachytherapy. J Radiat Res 59:333-337. https://doi.org/10.1093/jrr/rry030

18. Kawai Y, Tamura M, Amano M, Kamomae T, Monzen H (2019) Dosimetric Characterization of a Novel Surface Collimator With Tungsten Functional Paper for Electron Therapy. Anticancer Res 39:28392843. https://doi.org/10.21873/anticanres.13412

19. Monzen H, Kanno I, Fujimoto T, Hiraoka M (2017) Estimation of the shielding ability of a tungsten functional paper for diagnostic x-rays and gamma rays. J Appl Clin Med Phys 18:325-329. https://doi.org/10.1002/acm2.12122

20. Monzen H, Tamura M, Kijima K, Otsuka M, Matsumoto K, Wakabayashi K, Choi MG, Yoon DK, Doi H, Akiyama H, Nishimura $Y$ (2019) Estimation of radiation shielding ability in electron therapy and 
brachytherapy with real time variable shape tungsten rubber. Phys Med 66:29-35. https://doi.org/10.1016/j.ejmp.2019.09.233

21. Matsumoto K, Tamura M, Otsuka M, Wakabayashi K, Kijima K, Monzen H (2020) Dosimetric Characteristics of a Real Time Shapeable Tungsten Containing Rubber with Electron Beams. Nihon Hoshasen Gijutsu Gakkai Zasshi 76:1248-1255. https://doi.org/10.6009/jjit.2020_JSRT_76.12.1248

22. Wakabayashi K, Monzen H, Tamura M, Matsumoto K, Takei Y, Nishimura Y (2021) Dosimetric evaluation of skin collimation with tungsten rubber for electron radiotherapy: A Monte Carlo study. J Appl Clin Med Phys 22:63-70. https://doi.org/10.1002/acm2.13210

23. Kawai $Y$, Tamura M, Amano M, Kosugi T, Monzen H (2021) First Clinical Experience of Tungsten Rubber Electron Adaptive Therapy with Real-time Variable-shape Tungsten Rubber. Anticancer Res 41:919 LP-925. https://doi.org/10.21873/anticanres.14845

24. Japanese Industrial Standards (2012) Rubber, vulcanized or thermoplastic -Determination of hardness - Part 3: Durometer method. Japanese Standards Association, Tokyo

25. Japanese Industrial Standards (2017) Rubber, vulcanized or thermoplastic - Determination of tensile stress-strain properties. Japanese Standards Association, Tokyo

26. Kamomae T, Oita M, Hayashi N, Sasaki M, Aoyama H, Oguchi H, Kawamura M, Monzen H, Itoh Y, Naganawa S (2016) Characterization of stochastic noise and post-irradiation density growth for reflective-type radiochromic film in therapeutic photon beam dosimetry. Phys Med 32:1314-1320. https://doi.org/10.1016/j.ejmp.2016.07.091

27. Kaushik S, Punia R, Tyagi A, Malik A (2019) Effect of scattering and differential attenuation on beam profile in the presence of high-density intensity modifying compensator. J Cancer Res Ther 15:110. https://doi.org/10.4103/jcrt.JCRT_661_17

28. Ordonez-Sanz C, Bowles S, Hirst A, MacDougall ND (2014) A single plan solution to chest wall radiotherapy with bolus? $\mathrm{Br} J$ Radiol 87:20140035. https://doi.org/10.1259/bjr.20140035

29. Al-sudani TA, Biasi G, Wilkinson D, Davis JA, Kearnan R, Matar FS, Cutajar DL, Metcalfe P, Rosenfeld AB (2020) eXaSkin: A novel high-density bolus for 6MV X-rays radiotherapy. Phys Med 80:42-46. https://doi.org/10.1016/j.ejmp.2020.09.002

\section{Figures}


(a) No bolus

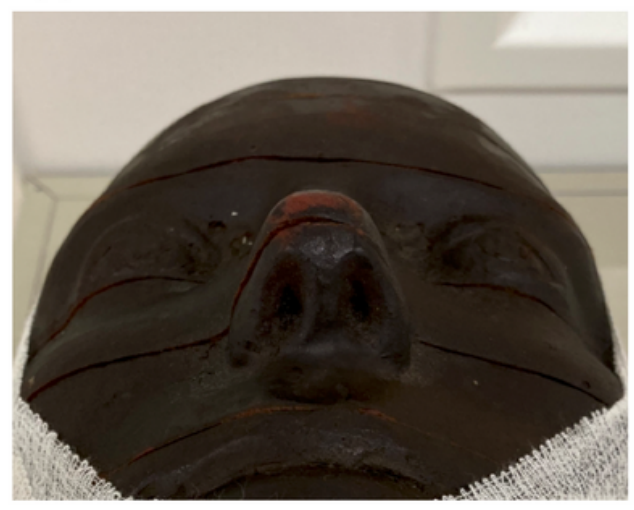

(b) STR bolus

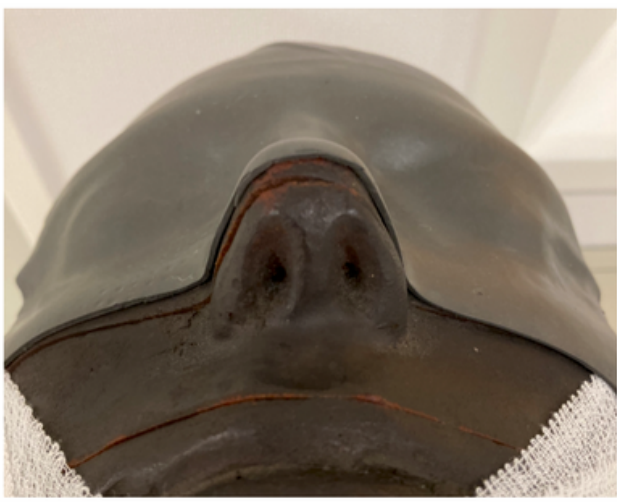

(c) Gel bolus

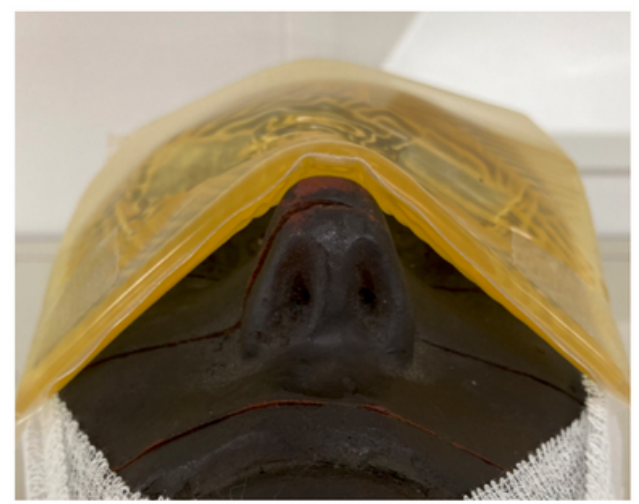

\section{Figure 1}

Clinical geometry setup without bolus (a), with STR bolus (b), and with gel bolus (c) on anthropomorphic head and neck phantom

(a) PDD

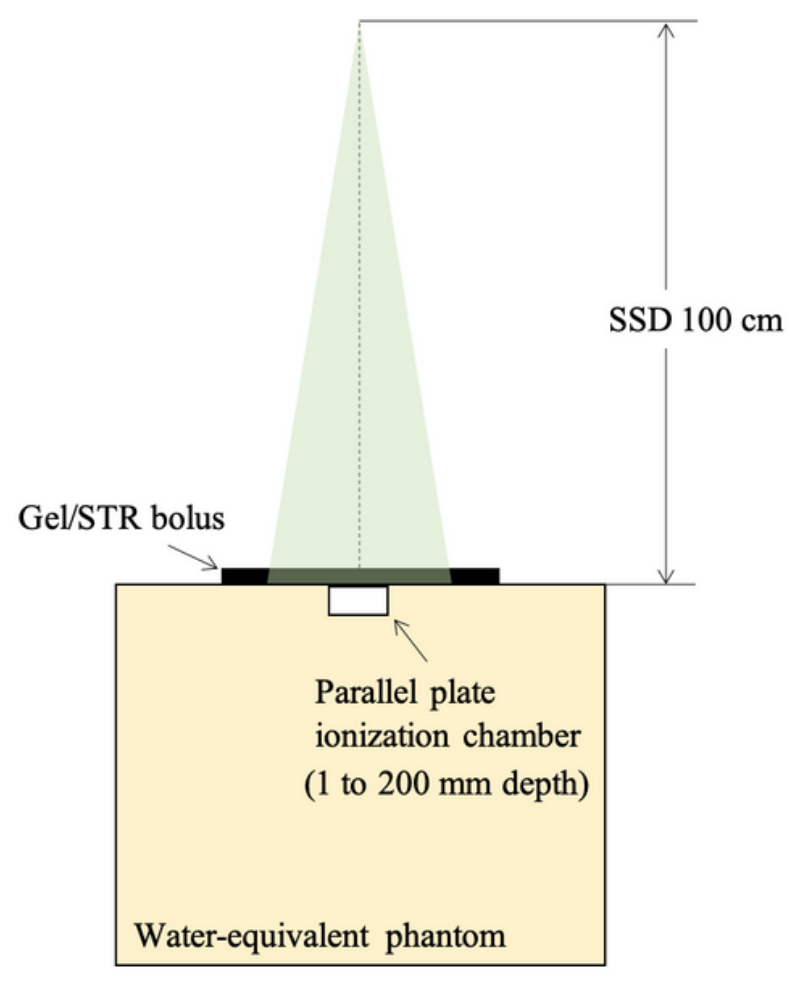

(b) Lateral dose profile

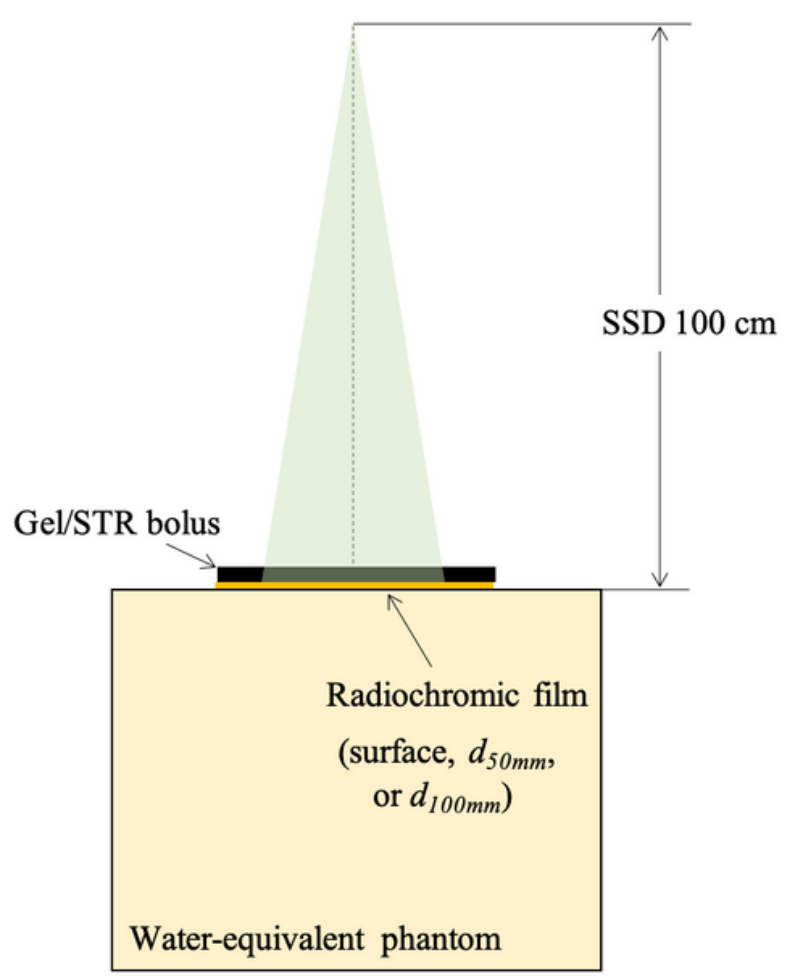

\section{Figure 2}

Measurement geometry of percentage depth dose (PDD) and lateral dose profile for 6-MV photon beams. (a) PDD, (b) lateral dose profile 


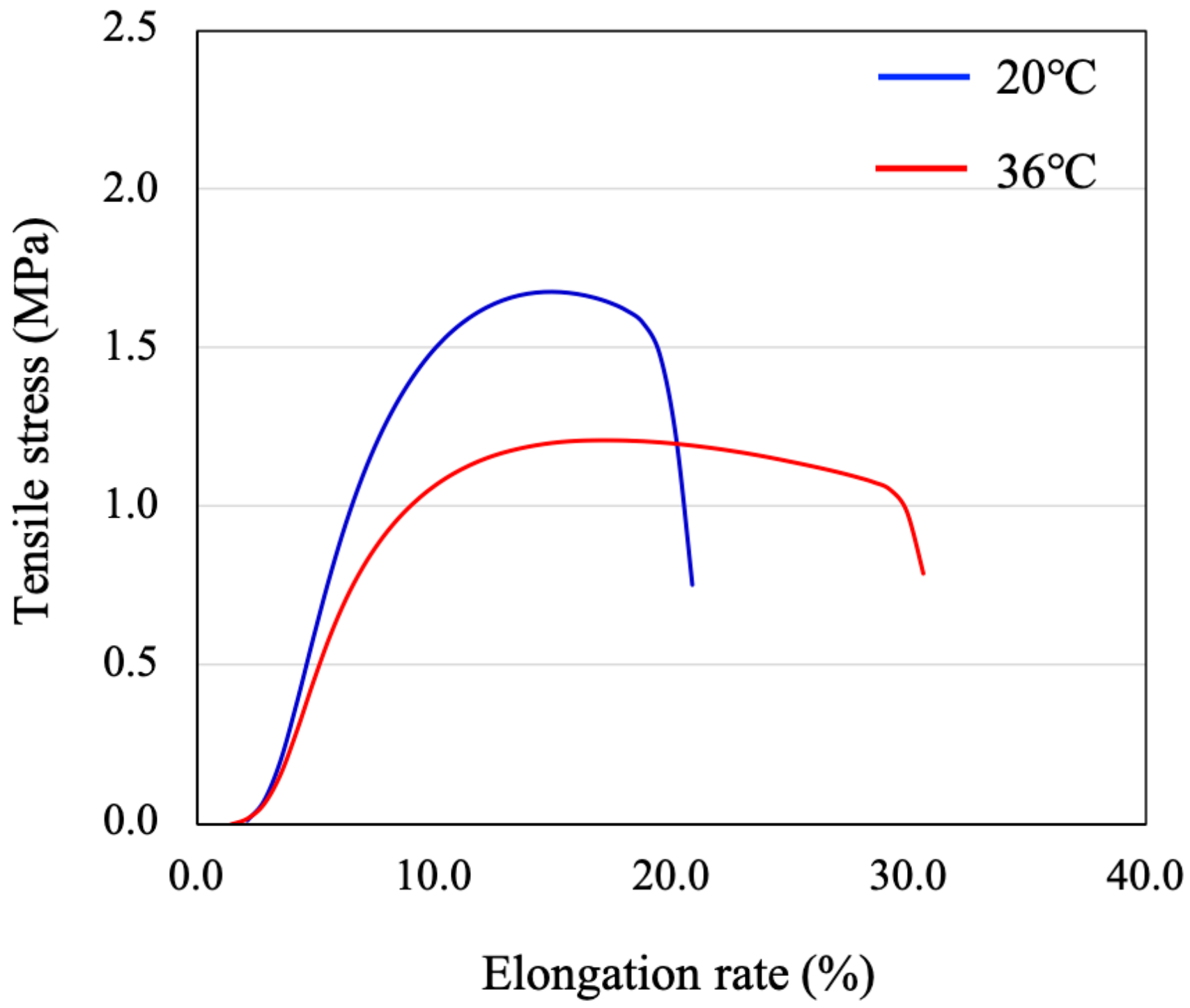

Figure 3

Tensile stress-elongation rate curves of STR at temperatures of $20^{\circ} \mathrm{C}$ and $36^{\circ} \mathrm{C}$ 
(a) Whole PDD

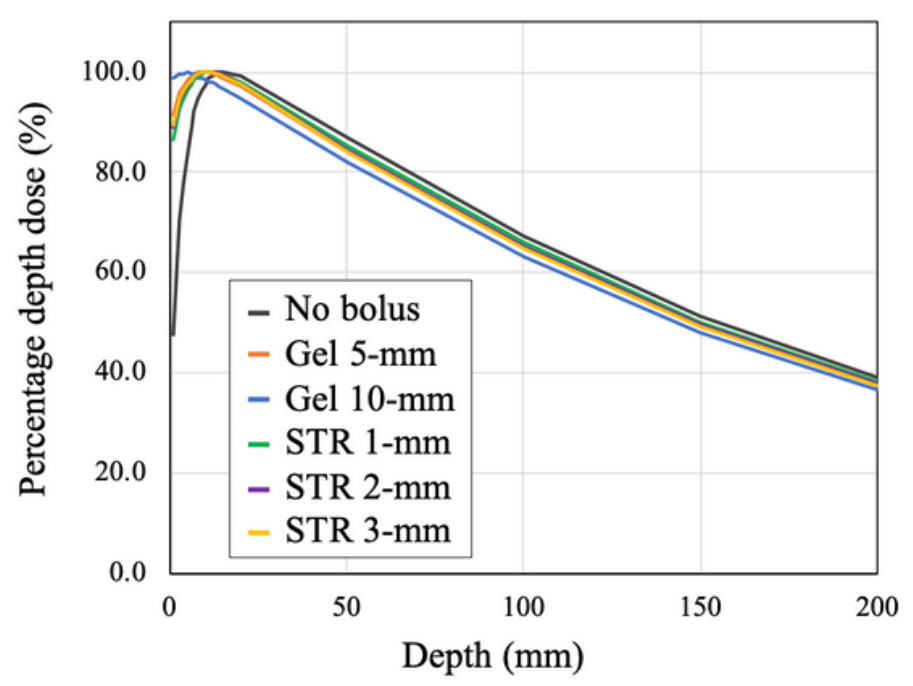

(b) Build-up region

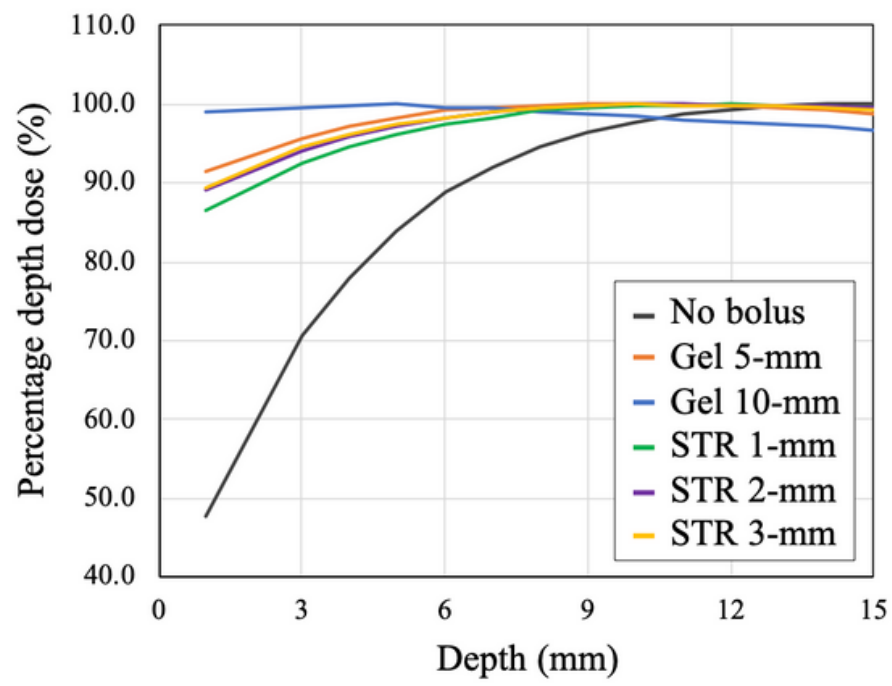

\section{Figure 4}

Percentage depth dose (PDD) curves of no bolus, gel bolus, and STR bolus. (a) Whole PDD, (b) Build-up region

(a) Surface

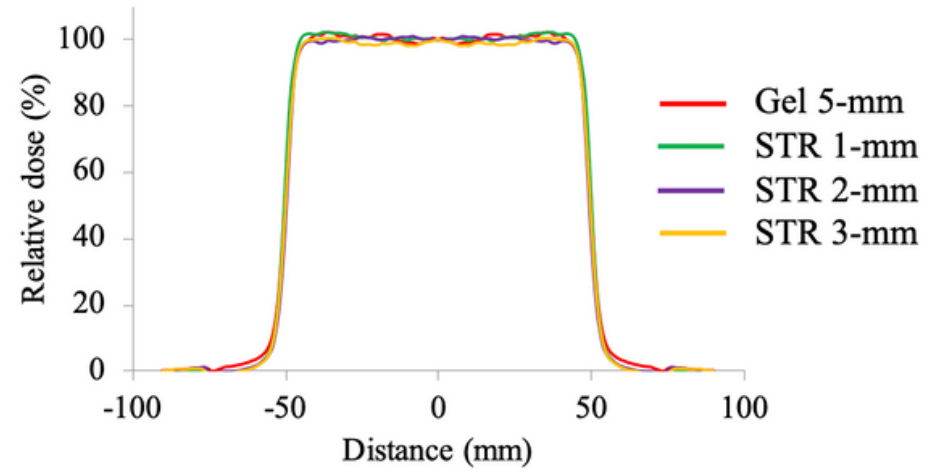

(c) $d_{100 \mathrm{~mm}}$

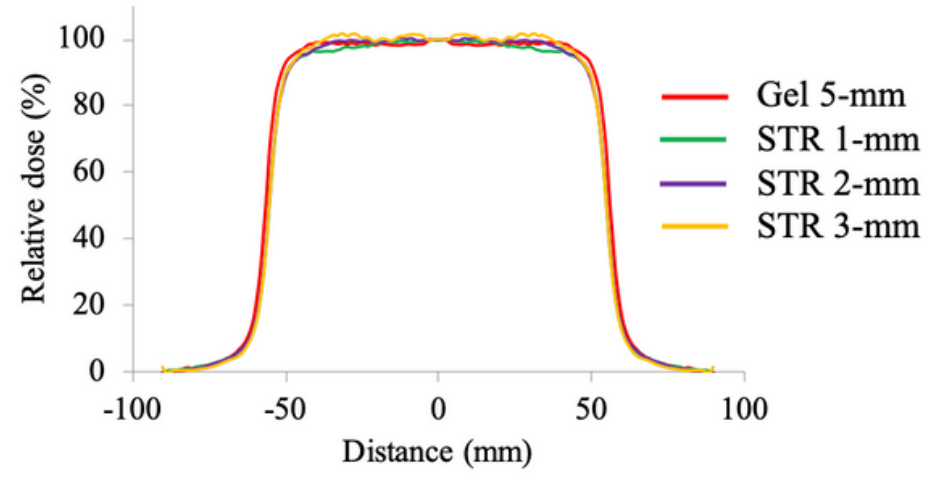

(b) $d_{50 \mathrm{~mm}}$

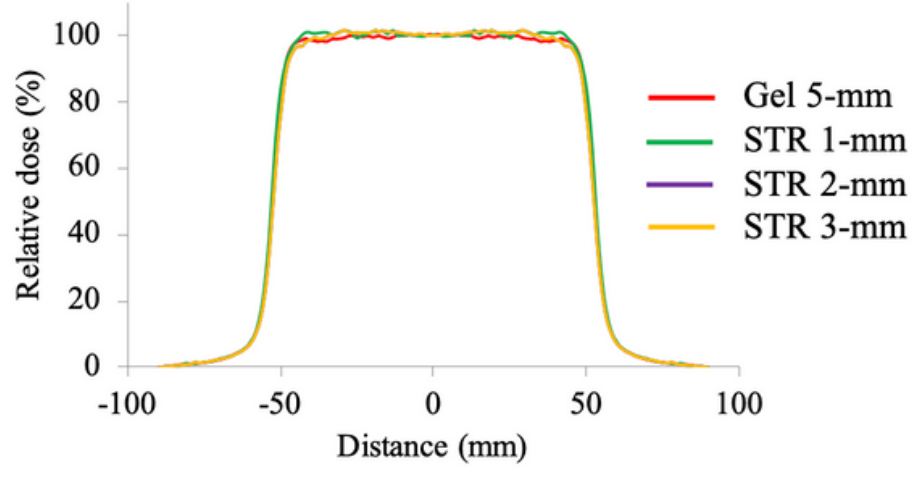

Figure 5

Lateral dose profiles of surface, d50mm, and d100mm in water-equivalent phantom 